\title{
Application of multi level fuzzy comprehensive evaluation method in water resources assessment
}

\author{
Qiming Chen \\ Department of Automation, North China Electric Power University, Baoding 071000, China. \\ 1132181030@qq.com
}

Keywords: Analytic hierarchy process, Water resources carrying capacity, Fuzzy comprehensive evaluation.

\begin{abstract}
Water resources issue is a big problem faced by the mankind. It is of great significance to make a correct evaluation and prediction of water resources carrying capacity in a country or region. However, lots of problems exist in the evaluation of water resources carrying capacity, such as too many evaluation indicators, difficulty in quantifying and the impact of subjective factors, etc. This paper proposes a hierarchical fuzzy comprehensive evaluation method based on analytic hierarchy process to measure the water resources carrying capacity of a region. In this paper, this model is applied to the evaluation of water resources carrying capacity of Beijing and Hubei province. Theoretical analysis and practical application show that the model is effective.
\end{abstract}

\section{Introduction}

Water resources issue is a big problem faced by the mankind. Aiming to measure the water resources condition, we establish an evaluation system and apply it to evaluatethe water resources of Beijing and Hubei in China.[1] In this paper,we establish a fuzzy synthetic evaluation model based on analytic hierarchy process.

Analytic hierarchy process is a structured technique for organizing and analyzingcomplex decision, based on mathematicsandpsychology.[2]It has particular application ingroup decision.Fuzzy comprehensive evaluation(FCE) means using fuzzy mathematics to make an overall evaluation of the object which is restricted by many factors[3][4]. It can well solve the problems which are fuzzy and hard to quantify.

In this paper, we take the weights of every indicator obtained from analytic hierarchy process into Fuzzy comprehensive evaluation, combining with their strength, to establish our FAHP model.

\section{Model Framework}

\subsection{How to select index?}

- Substitute the index like growth rate and percentage for the index that is an absolute magnitude, which is more representative[5].

- Notice the respective characteristics of different regions. Choosing a good index that is suitable for different regions is of importance.For example, as there is a vast territory with a sparse population in some areas, the natural population growth rate is better than population density.

- Consider whether the index is accessible to get.

\subsection{The framework of our model}

According to Figure 1 , we make Water resource, Ecological environment, Social economy as our criterion layer, taking 12 indexes into account to analyze.[6][7] 


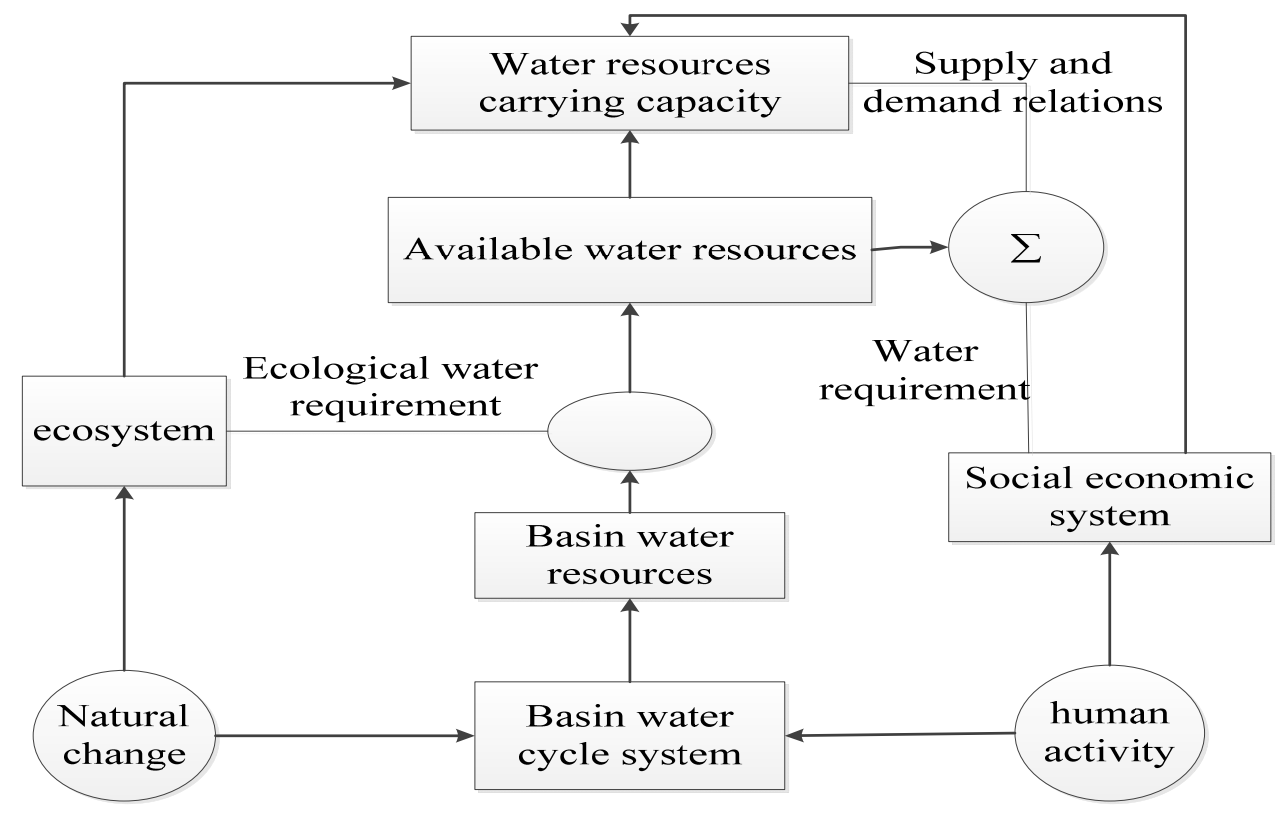

Figure 1 Relationship of water resources carrying capacity system

The determination of the critical value and the ideal standard of the water resources carrying capacity directly affects the accuracy, objectivity and practicability of the evaluation results. Through expert consultation and reference to the relevant indicators of sustainable development of the international and domestic authorities to determine the various water resources carrying capacity of the individual standard index values.

These 12 indicators are Average water resource amount capita (C1), Rate of resource utilization (C2), Per capita water consumption (C3), Vegetation coverage (C4), COD concentration (C5), Ecological water requirement ratio (C6), the natural population growth rate (C7), The level of urbanization (C8), Per capita GDP (C9), The proportion of tertiary industry in GDP (C10), The per capita share of grain (C11), Water Efficiency (C12).

The model of analytic hierarchy process is shown in Figure 2.

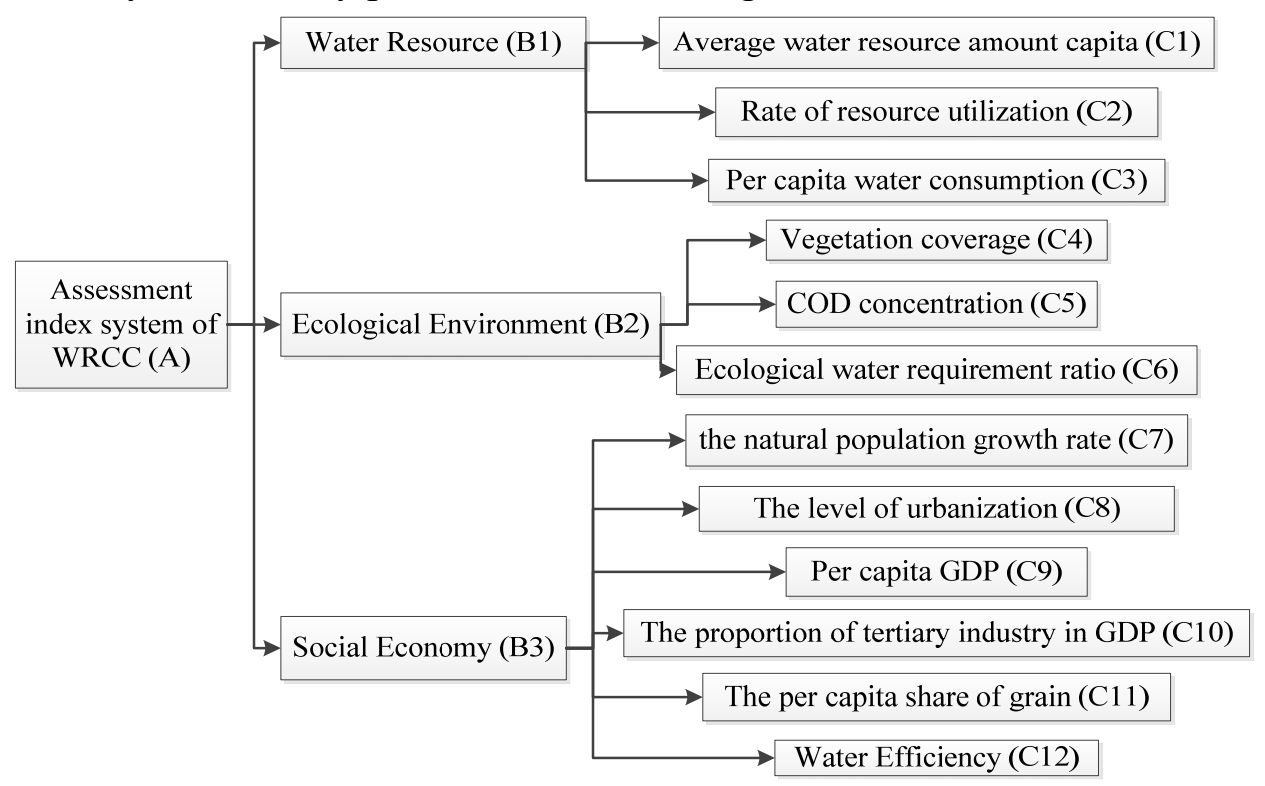

Figure 2The Framework of Evaluation Model

Step 1: Confirm Judgment Matrix

Some authoritative figures of the sustainable development and some other related indexes, we can determine each single index of the water resources carrying capacity. Take matrix A as an example ,judegemen matrix of $\mathrm{A}$ is shown in the Table 1. 
Table 1 Judgement Matrix

\begin{tabular}{llll}
\hline Matrix A & B1 & B2 & B3 \\
\hline B1 & 1 & $2 / 3$ & $5 / 9$ \\
B2 & $3 / 2$ & 1 & $5 / 6$ \\
B3 & $9 / 5$ & $6 / 5$ & 1 \\
\hline
\end{tabular}

We can get the residual judgment matrix by the same method.

Step 2: Consistency check and acquirethe relevant weights

Use MATLAB to calculate the value of CR by the equations.

$$
C I=\frac{\lambda-n}{n-1}, C R=\frac{C I}{R I}
$$

From the result in Table 2, we can knowthe coherence of those matrix is qualified.

Table 2 CR of every matrix

\begin{tabular}{lllll}
\hline & Matrix A & Matrix B1 & Matrix B2 & Matrix B3 \\
\hline CR & $7.66 \times 10^{-16}$ & 0 & 0.081 & 0.0011 \\
\hline
\end{tabular}

Step 3:Combinational Consistency Test

$$
C R=\frac{C I}{R I}=0.0198<0.1
$$

So , the combinational coherence of those matrix is qualified and we can get weights of every index which are show in Table 3.

\begin{tabular}{|c|c|c|c|c|c|c|c|}
\hline $\begin{array}{l}\text { Target } \\
\text { layer }\end{array}$ & $\begin{array}{l}\text { Criterion } \\
\text { layer }\end{array}$ & weight & $\begin{array}{l}\text { Index } \\
\text { layer }\end{array}$ & Weight & $\begin{array}{l}\text { Weight to } \\
\text { target layer }\end{array}$ & V1 & $\mathrm{V} 2$ \\
\hline \multirow{12}{*}{ A } & \multirow{3}{*}{ B1 } & \multirow{3}{*}{0.2326} & C1 & 0.6522 & \multirow{4}{*}{$\begin{array}{l}0.1517 \\
0.0506 \\
0.0303 \\
0.153\end{array}$} & 1700 & \multirow{2}{*}{4000} \\
\hline & & & $\mathrm{C} 2$ & 0.2174 & & 30 & \\
\hline & & & $\mathrm{C} 3$ & 0.1034 & & 800 & \multirow{2}{*}{$\begin{array}{l}400 \\
60\end{array}$} \\
\hline & \multirow{3}{*}{ B2 } & \multirow{3}{*}{0.3488} & $\mathrm{C} 4$ & 0.4387 & & 15 & \\
\hline & & & C5 & 0.2381 & 0.0831 & 30 & 15 \\
\hline & & & C6 & 0.3232 & 0.1127 & 25 & 50 \\
\hline & & & C7 & 0.1951 & 0.0817 & 9.5 & 2.1 \\
\hline & & & $\mathrm{C} 8$ & 0.048 & 0.0201 & 20 & 70 \\
\hline & B3 & 0.4196 & C9 & 0.2753 & 0.1152 & 3280 & 32800 \\
\hline & & & C10 & 0.146 & 0.0611 & 30 & 60 \\
\hline & & & $\mathrm{C} 11$ & 0.03 & 0.0126 & 300 & 590 \\
\hline & & & C12 & 0.3056 & 0.1279 & 3.07 & 408.6 \\
\hline
\end{tabular}

Table 3 Assessment index system of water resources carrying capacity

Step 4: Measurement of water resources carrying membership

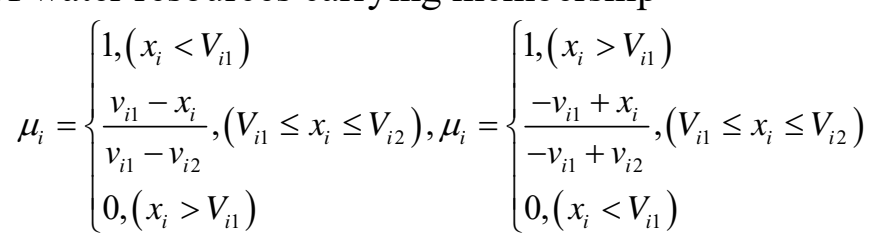

The formeris suitable forthe situation that the water resources carrying capacity is getting smaller when the index gets larger. The latter is contrarywiththe former.

We use the classification criteria in the Table 4.

Table 4 Classification criteria

\begin{tabular}{llllll}
\hline & 0 & $0 \sim 0.2$ & $0.2 \sim 0.8$ & $0.8 \sim 1$ & 1 \\
\hline Type & Unable to carry & Possible to carry & Able to carry & Easy to carry & Optimal to carry \\
\hline
\end{tabular}




\section{APPLICATION}

In this part, we put related data of Beijing and Hubei Province into ourmodel. The result is as shown in Table 5.

Table 5 Classification of Beijing and Hubei

\begin{tabular}{|l|l|l|}
\hline Place & Beijing & Hubei \\
\hline Value & 0 & 0.2618 \\
\hline Type & Unable to carry & Able to carry \\
\hline
\end{tabular}

Results of Classification of Beijing and Hubei show that the model is very satisfactory and comform to reality.

\section{Summary}

In this paper, we establish we establish a fuzzy synthetic evaluation model based on analytic hierarchy process and this model is applied to the evaluation of water resources carrying capacity of Beijing and Hubei province. Theoretical analysis and practical application show that the model is effective.

\section{References}

[1] Zhu Yizhong, Xia Jun, Tan Ge. Prediction and evaluation of water resources carrying capacity in northwest region of China [J]. resources science, 2003,04:43-48.

[2]He Fuyan, Wang Liang. Grid regional ecological security evaluation method of [J]. remote sensing information, 2016, v.31; No.14301:25-30.

[3] Zhou Yue, zhouyuehua, ye Limei, Xu Gaozheng. Drought and flood disaster in Hubei Province induced preliminary study [J]. Meteorological disaster law, 2016, v.42; No.49402:221-229.

[4] Shen Zhidong. Using analytic hierarchy process to construct the performance evaluation system of state owned enterprises [J]. audit research, 2013, No.17202:106-112.

[5] Guo Jinyu, Zhang Zhongbin, Sun Qingyun. Research and application of analytic hierarchy process [J]. Chinese Journal of safety science, 2008,05:148-153.

[6] Yu Weidong. Study on water resources carrying capacity of the Loess Plateau -- a case study of Hejin City, Shanxi province [D]. Nanjing Meteorological Institute, 2003

[7] Xia Jun, Zhu Yizhong. Water resources security metrics: water resources bearing force research and challenges [J]. Journal of natural resources, 2002,03:262-269. 